\title{
AS CLASSES SOCIAIS EM MARX: retrospectiva e atualidade
}

\section{Marconi Gomes da Silva1 Denílson da Silva Araújo² William Eufrásio Nunes Pereira ${ }^{3}$}

\section{Introdução}

Nas sociedades de classe os meios de produção garantem aos seus proprietários maior e melhor quantidade da riqueza social produzida. Tem sido assim desde os tempos onde 0 trabalho escravo constituía a base da produção de excedente. Na sociedade escravista o escravo não participava do rateio da riqueza produzida que pertencia, em sua plenitude, ao proprietário de escravos. No sistema feudal o servo tinha participação em uma pequena parte da riqueza produzida podendo inclusive utilizar a terra e alguns instrumentos de trabalho (como 0 arado) pertencentes ao feudo, mas pertencia aos senhores feudais e eclesiásticos a propriedade dos meios de produção e a maior parte do excedente da economia.

A ascensão do modo de produção capitalista privou a classe trabalhadora de ser proprietária de parte do produto e, portanto, do excedente da economia. $\mathrm{O}$ acesso à riqueza produzida ocorre por via de uma remuneração média que, a priori, garante a reprodução física do trabalhador aprofundando assim, diferentemente do feudalismo, a divisão da riqueza entre as diferentes classes e estratos de classes sociais. Sob o capitalismo, o embate político, social e econômico tem sido mais acirrado entre o capitalista burguês e 0 trabalhador. Todavia, 0 atrito entre as classes sociais no capitalismo não está restrito apenas aos "polares" interesses entre esses dois agentes. Marx foi um dos estudiosos sobre a divisão das sociedades em classes sociais. Sem embargo, ainda hoje existe uma significativa discussão histórico-teórica sobre a existência ou não de uma teoria das classes sociais em Marx.

\footnotetext{
1 Prof. Adjunto do Departamento de Economia da UFRN. Doutorado em Ciências Sociais (UFRN). Mestrado em Economia do Trabalho (UFPB). Professor do Departamento de Economia da Universidade Federal do Rio Grande do Norte (DEPEC/UFRN). https://orcid.org/0000-0002-2382-5094

2 Prof. Adjunto do Departamento de Economia da UFRN. Mestre em Economia Agrícola e Regional pela Universidade Federal da Paraíba Campus II. Doutor em Desenvolvimento Econômico pela Universidade Estadual de Campinas.

${ }^{3}$ Bacharel em Economia e Direito. Especialista em Gestão dos Recursos Humanos. Mestre em Economia e Doutor em Ciência Sociais. Professor Associado no Departamento de Economia da Universidade Federal do Rio Grande do Norte.
} 
Desta forma, após estabelecer os termos do debate sobre a existência ou não de uma teoria das classes sociais em Marx, um dos objetivos do corrente artigo é colocar em evidência que a discussão sobre classes sociais em Marx não está limitada à obra $O$ Capital, podendo ser encontrada em outros tratados políticos e econômicos do autor. Para a concretização desse objetivo partiu-se da hipótese de que a desigualdade na distribuição da riqueza produzida tanto dificulta a estratificação social quanto acirra os antagonismos e as contradições entre os interesses das classes e estratos de classes sociais.

Assim, além dessa pequena introdução o artigo está dividido em 5 seções mais as considerações finais. Na seção 2 buscou-se registrar a discussão e o entendimento sobre classes sociais em Marx, além de estabelecer o debate da existência ou não de uma contribuição mais robusta de Marx à referida temática. Na seção 3, buscou-se registrar "a complexa organização do trabalho em classe social" com base em vários trabalhos de Marx. Na seção 4 foi introduzida uma breve reflexão sobre a ascensão e o papel da classe média no contexto social, político e econômico do sistema capitalista onde foi enfatizado como uma de suas características o caráter reacionário marcado pela oscilação entre a ascensão econômica à pequena burguesia e 0 retrocesso ao proletariado. Na seção 5 buscou-se enfatizar que existem alguns estudos de referência que serviram para auxiliar a análise da estrutura de classes sociais no Brasil, a exemplo do que fez Santos (2002) utilizando como referência as análises de Wrigth (1997). Por fim, na seção 6 foram registradas algumas considerações finais.

\section{0 entendimento de Marx sobre as classes sociais}

Segundo alguns autores, a discussão sobre as classes sociais em Marx apresenta-se incompleta. Esta incompletude seria expressa em parte pelo fato de que Marx nunca teria abordado especificamente o tema. O capítulo intitulado As classes, capítulo LII, Livro III de 0 Capital, em que Marx enfocaria exclusivamente 0 assunto teve 0 manuscrito interrompido bruscamente, ficando, portanto, inconcluso. Um outro aspecto revelador de tal incompletude seria o fato de haver ocorrido intensas mudanças nas sociedades capitalistas desde a época de Marx até a contemporaneidade, de modo que a teorização marxiana das classes sociais, dispersa ao longo da sua obra, ter-se-ia tornado anacrônica ou insuficiente (GIDDENS, 1975; POULANTZAS, 1978). Há, entretanto, autores que defendem que a obra de Marx apresenta uma teoria das classes sociais com forte capacidade explicativa das relações entre os diferentes agrupamentos sociais nos países capitalistas na contemporaneidade (HIRANO, 2002; LESSA, 2006). 
Embora sem a intenção de proceder a uma arqueologia do tema das classes sociais, é importante tomar como ponto de partida o fato de que somente a partir do momento em que os homens passaram a produzir excedentes econômicos foi possível a estratificação ou diferenciação social, ou seja, a constituição de agrupamentos humanos vivendo do trabalho de outrem. Nesta situação, os produtores das condições materiais da existência passaram a produzir além do necessário à reposição dos meios (instrumentos e objetos) de trabalho, bem como dos meios de subsistência.

Efetivamente, foi em momento posterior ao das denominadas sociedades de comunismo primitivo que tal exigência material encontrou-se presente na história da humanidade. $\mathrm{Na}$ realidade, essa condição material ocorreu articuladamente ao processo de divisão do trabalho entre distintos grupos tribais e ao advento da propriedade privada dos meios vitais à produção. Concretamente, pressuposta a existência do excedente econômico, esta última constitui-se em condição fundamental para a diferenciação social de grupos humanos e para as diferentes formas de inserção no processo de produção. Por sua vez, estas diversas formas de inserção produtiva são a expressão de variadas funções exercidas pelos distintos grupos sociais que passam a constituir diferenciados grupos de interesses e que frequentemente se encontram ou em luta na defesa de interesses imediatos (econômicos) ou políticos (transformação da sociedade).

Com base no posicionamento acima apresentado, uma das ideias existentes no seio do pensamento marxista é que, exclusive a experiência das sociedades primitivas, as demais sociedades seriam marcadas pela presença de classes sociais. Para reforçar essa ideia, frequentemente é citada a passagem do Manifesto do partido comunista em que é afirmado: "Até hoje, a história de todas as sociedades que existiram até nossos dias tem sido a história da luta de classes" (MARX e ENGELS, 19--a, p. 21). Assim, a interpretação, ancorada em Marx e Engels, é que a distinção sob a forma de classe acompanha todas as sociedades em que existe a propriedade privada dos meios de produção. Logo, em períodos anteriores ao capitalismo, somente as sociedades que vivenciaram o modo de produção asiático, caracterizado pela propriedade estatal não teriam passado pela experiência da estratificação social sob a forma de classes sociais.

A existência de propriedade privada, no entanto, não determina que as sociedades tenham na classe a única forma de estruturação dos diferentes agrupamentos sociais. Segundo Bottomore, Marx e Engels tinham clareza quanto à existência de "conflitos entre grupos de status" (BOTTOMORE, 1997, p. 62). Assim, afirma:

"as castas se enquadrariam numa categoria que Marx e Engels distinguiram quando escreveram que 'nas primeiras épocas da história, encontramos em quase toda parte uma complicada disposição da sociedade em várias ordens, uma gradação múltipla de categorias sociais" (BOTTOMORE, 1997, p. 56). 
De acordo com Hirano (2002), embora Marx não tenha abordado especificamente o tema das castas, em várias de suas obras fez "alusões a castas na Índia e no Egito" (HIRANO, 2002, p. 36). Acrescenta, "A chave estrutural da análise marxista do sistema de castas é a produção social - as 'condições materiais da produção"', ou seja, uma produção determinada que "envolve um tipo determinado de divisão do trabalho e relações sociais de produção". Concretamente, o regime ou sistema de castas corresponde a "tipo particular de trabalho' baseado na 'mestria' ou habilidade artesanal", ou seja, "é uma forma particular e determinada da divisão do trabalho" (HIRANO, 2002, p. 40) em que o trabalhador constitui-se num "proprietário que trabalha", os instrumentos de trabalho apresentam-se como "meio para o trabalho individual" (HIRANO, 2002, p. 39) e a perícia profissional é "transmitida de geração em geração e de pais a filhos"' (HIRANO, 2002, p. 38). Logo, a "organização de castas é incompatível com a escravidão e a servidão" e reflete "determinados estágios de desenvolvimento da produção" (HIRANO, 2002, p. 36).

A partir de fragmentos compilados, o autor destaca que "os [...] elementos constitutivos da formação social de castas" são os seguintes: "a) o trabalho vitalício ou o caráter hereditário das profissões; b) seu resultado é especialização extrema; c) diferenciação entre as diversas espécies ou subespécies, ou o exclusivismo de umas em relação às outras em termos da monopolização das atividades profissionais; d) formam grupos sociais impermeáveis; e) os 'destinos sociais' como produtos de "leis sociais'” (HIRANO, 2002, p. 38). Pode-se ainda destacar, com base em Hirano (2002), que o regime de castas se constituiu apenas em "uma das alternativas de formação social pré-capitalista", que, no entanto, não foi comum a todas essas formas de organização social (HIRANO, 2002, p. 15).

Outro tipo de relação que marcou a estratificação de agrupamentos sociais em contexto pré-capitalista foi a estamental. Uma particularidade fundamental é que este tipo de relação foi característico do modo de produção feudal e apresentou-se dominante na parte da Europa onde teve vigência a propriedade feudal até o momento em que de sua desintegração resultou a moderna sociedade burguesa. Ou seja, a transição do feudalismo ao capitalismo foi a transição de um Estado absolutista, caracteristicamente feudo-estamental, para um Estado moderno burguês, marcadamente capitalista e de classes (HIRANO, 2002). A ideia para Marx é que "a uma determinada divisão do trabalho social corresponde um determinado tipo de estratificação social" (HIRANO, 2002, p. 77).

O 'mundo feudal' foi uma realidade fundada no campo, tendo como agrupamentos opostos os senhores feudais e eclesiásticos e os servos. Neste contexto, "A organização hierárquica da propriedade territorial e, em relação com esta, as congregações armadas davam à nobreza 0 
poder sobre os servos". Obviamente, "Esta organização feudal era [...] uma associação ante a classe dominada" (MARX apud HIRANO, 2002, p. 79. Acrescenta Hirano (2002) que "Nas cidades, a esta organização feudal da propriedade territorial correspondia, segundo as palavras de Marx, a propriedade corporativa, a organização feudal do artesanato, emergindo com esta organização os grêmios" (HIRANO, 2002, p. 79). Assim, na relação estabelecida entre "oficiais e aprendizes" foi reproduzida "nas cidades, uma hierarquia semelhante à que imperava no campo" (MARX apud HIRANO, 2002, p. 79) e do ponto de vista da divisão do trabalho, "Na agricultura, a divisão do trabalho via-se entorpecida pelo cultivo parcelado, junto ao qual surgiu depois a indústria em domicílio dos camponeses; na indústria, não existia divisão do trabalho no interior de cada ofício e muito pouca divisão entre os diversos ofícios" (MARX apud HIRANO, 2002, p. 80).

Por sua vez, "os estamentos são instituições feudais que persistiram até os séculos XVII, XVIII e XIX como sequelas jurídicas, econômicas, sociais e políticas do modo de produção feudal, na Inglaterra, França, Espanha e Alemanha, respectivamente aos referidos séculos". A "organização estamental correspondia à formação social imediatamente anterior à organização da sociedade em classes" ou sociedade burguesa (HIRANO, 2002, p. 84).

Na obra A ideologia alemã, Marx e Engels mostram o processo histórico que redundou na transformação acima mencionada - a dissolução da sociedade feudal e a 'emergência' da ordem burguesa. Nesta obra, afirmam: "'Dos diversos grupos de vizinhança locais das diferentes cidades, foi surgindo, paulatinamente, a classe burguesa", tendo por base condições de vida que se tornaram crescentemente comuns. Então, "Ao entrarem em contato as cidades umas com as outras, estas condições comuns se desenvolveram até se converterem em condições de classe [...] idênticos costumes"'. Segundo asseveram, a burguesia "'cinde-se, sob a ação da divisão do trabalho, em diferentes frações, absorvendo, por último, as classes possuidoras preexistentes'”. De outra parte, a classe despossuída e parte da classe possuidora com menores posses tornouse proletária, ou em classe oposta à burguesia, pois "Os diferentes indivíduos somente formam uma classe enquanto se veem obrigados a sustentar uma luta comum contra outra classe"' (MARX e ENGELS apud HIRANO, 2002, p. 131-2). Em obra posterior, no livro A miséria da filosofia, a ideia da oposição entre burguesia e proletariado foi retomada e teve sua gênese reafirmada como tendo origem nas condições econômicas (MARX, 1985).

Na realidade, não há aqui o propósito de se proceder a uma ampla exposição sobre a gênese das classes fundamentais das sociedades capitalistas. O propósito com a exposição precedente foi, tão-somente, destacar o fato de que as mesmas foram gestadas no seio das sociedades feudal-estamentais europeias, em um longo período que decretou a superação da 'ordem' pré-existente. Além disso, é importante destacar que uma vez que o capitalismo se afirmou 
como modo de produção dominante e que vários países se articularam ao sistema-mundo, através de processos históricos diferentes, passaram por distintas experiências de estruturação de classes sociais, a partir de modificações das estruturas sociais preexistentes. Ou seja, com a participação na ordem regida pelo capital ocorreram, no interior das diferentes sociedades, processos específicos de formação de classes sociais. Logo, é, efetivamente, a estruturação das classes sociais no capitalismo o foco dessa parte do estudo.

Apresentado o percurso anterior sobre estratificação social, retoma-se a referência inicial, ou seja, o capítulo inconcluso de Marx sobre as classes sociais, para abordar de modo mais apropriado esta temática. Segundo Marx, no capítulo LII (inacabado), livro III, intitulado As classes, o percurso apresentado ao longo da sua obra foi revelador de que "a tendência constante e a lei do desenvolvimento do modo de produção capitalista é separar cada vez mais do trabalho os meios de produção e concentrar cada vez mais em grandes grupos os meios de produção dispersos, portanto transformar o trabalho em trabalho assalariado e os meios de produção em capital". O resultado seria então que proprietários de força de trabalho, capital e terra constituíssem "as três grandes classes da sociedade moderna, que se baseia no modo de produção capitalista". O passo seguinte foi a indagação sobre o que faz com que "assalariados, capitalistas e proprietários de terra se tornem os formadores das três grandes classes sociais". Em seguida, começou a responder: "À primeira vista, a identidade de rendimentos e as fontes de rendimento" (MARX, 1985-6, p. 317). Dando prosseguimento à sua argumentação afirmou que se tal explicação fosse válida para os agrupamentos sociais em foco, também deveriam constituir classes sociais, os médicos e funcionários públicos, dentre outros, uma vez que tal identidade também existe nesses casos. Entretanto, o manuscrito foi bruscamente interrompido.

A princípio, é necessário ter em vista que a base material da reflexão de Marx nesta parte de O Capital era a Inglaterra, pois se tratava do país em que a estrutura econômica se encontrava "desenvolvida ao máximo, do modo mais clássico" e no qual os aspectos constitutivos das classes encontravam-se plenamente desenvolvidos (MARX, 1985-6, p. 317). Na realidade, embora 0 capítulo tenha encerramento brusco é possível observar que a apresentação de três classes como as grandes classes da sociedade moderna, de algum modo expressa especificidades presentes no caso da Inglaterra, o que se revela diferente de outras obras, dentre as quais 0 Manifesto do partido comunista, A ideologia alemã, A miséria da filosofia, outras partes de O Capital, em que afirma que são duas as classes fundamentais do capitalismo.

De qualquer modo, a "linha demarcatória" das classes sociais encontra-se claramente explicitada: a propriedade dos meios de produção. É esta propriedade que se encontra crescentemente concentrada em mãos de grupos que se opõem aos que trabalham para outrem 
que delimita os grandes agrupamentos denominados classes sociais. Então, segundo este critério, capitalistas e proprietários de terra são agrupáveis na categoria dos proprietários dos meios de produção e, portanto, integrantes de um mesmo grupo de interesse, ainda que existam conflitos internos de interesses aos integrantes desta categoria, relativamente aos que se veem forçados a assalariar-se. Na verdade, essa agregação é perfeitamente compatível com a passagem do Manifesto em que Marx e Engels denominam os "proprietários dos meios de produção social, que empregam o trabalho assalariado" de "classe dos capitalistas modernos" ou "burguesia" (MARX e ENGELS, 19--a, p. 21). Na verdade, "'a grande proprietária territorial também [...] tornou-se burguesa com o desenvolvimento da sociedade moderna'" (HIRANO, 2002, p. 149, texto nosso).

A burguesia constitui-se em classe social presente em qualquer sociedade em que tenha vigência relações capitalistas de produção, quer se trate de sociedade com relações capitalistas muito desenvolvidas ou não. O papel primordial da burguesia é, portanto, a partir da propriedade dos meios de produção exercer o comando sobre os trabalhadores e a extração do mais-trabalho. Na realidade, a burguesia que comanda o trabalho produtivo, ou o trabalho produtor do conteúdo material da riqueza, exerce uma função decisiva em sociedades capitalistas, pois é a atividade exercida sob o seu controle ou controlado sob a sua delegação que produz o excedente que se constitui em objeto de repartição entre diferentes frações burguesas, em decorrência das distintas funções que exercem para a reprodução global do capital.

As distintas frações do capital, em termos gerais, exercem "funções produtivas" ou funções vinculadas ao processo de "circulação". Assim, sob esta ótica, se constituem em frações da burguesia, as burguesias agrária e industrial, bem como as burguesias bancária, comercial etc. A burguesia pode ainda ser classificada de acordo com as magnitudes dos capitais de sua propriedade. Assim, pode-se classificar como grande burguesia ao conjunto dos detentores de grandes aportes de capital e simplesmente de burguesia ao conjunto dos detentores de capitais de menores magnitudes. Nas fases capitalistas anteriores a preponderantemente financeira uma aproximação para a classificação da grande burguesia e da burguesia é a quantidade de trabalhadores ocupados, pois se se entende capital como relação social que envolve dominação e controle, ocupar uma maior quantidade de trabalho significa maior comando sobre os trabalhadores e, portanto, "maior" é a burguesia, à medida que consegue comandar um maior contingente de trabalhadores.

É verdade que no seio do marxismo foi estabelecida uma discussão, propiciada pelo advento das sociedades por ações, em que se indagava se a questão fundamental era a propriedade jurídica - controle econômico dos meios de produção e dos produtos - ou a posse capacidade de colocar em operação os meios de produção. De acordo com o critério adotado, 
atribuições desenvolvidas, a princípio, por capitalistas passaram a ser atribuições de diretores e gerentes. Destaca-se que a perspectiva adotada neste trabalho é a mesma dos autores que consideram "que as proporções da 'separação entre a propriedade e o controle' têm sido muito exageradas e que uma 'classe proprietária' ainda domina a economia". São autores afinados com esta perspectiva: Mandel (1985), Whight (1981) e Scott (1979). Estes autores encontram-se referenciados por Bottomore (1997, p. 39).

Sob a égide do capital é correto afirmar que a burguesia constitui-se em classe reacionária, ou seja, que anseia e defende a perpetuação dessa forma de organização social. Todavia, deve ser observado que no momento da transição do feudalismo ao capitalismo ou de realização do "projeto" da burguesia, esta pôde exercer um papel revolucionário pois, tratava-se de um momento propício à generalização ou de tornar "comuns" ou "gerais" interesses de uma classe específica: a burguesia (MARX, 19--b; HIRANO, 2002). A burguesia pode ainda ser destacada como revolucionária em decorrência de um outro aspecto: o revolucionamento continuado das forças produtivas materiais. Segundo Marx, foi sob a ação da burguesia que a humanidade experimentou os maiores avanços das forças produtivas. Assim, sob este aspecto, nenhuma outra classe teria sido tão revolucionária quanto ela (MARX e ENGELS, 19--a, p. 23-4; MARX , 19--b, p. 216). Evidencia-se que esta foi a perspectiva adotada por Marx para referir-se à burguesia nas obras com caráter eminentemente histórico tais como $O$ dezoito brumário e $A$ revolução espanhola, ou seja, quando se tratava de destruir a ordem feudal e erigir a ordem capitalista. O mesmo não tendo acontecido no caso de 0 capital, pois, neste caso, o foco é o capitalismo já constituído, ou seja, onde o caráter revolucionário da burguesia quanto aos meios de produção tem como propósito central vencer a luta concorrencial às expensas da classe trabalhadora. Nesse caso, o propósito revolucionário tem uma faceta claramente reacionária.

Como o propósito central deste item do estudo é a abordagem da sociedade de classes ou da sociedade capitalista, trata-se, portanto, de destacar de um lado os detentores do capital e, de outro, a classe trabalhadora, ou mais precisamente o proletariado, pois trata-se efetivamente do segmento da classe trabalhadora que se constitui em grupo de oposição à burguesia. Como 0 agrupamento dos detentores de capital já foi objeto de apreciação, enfoca-se, a seguir, o conjunto dos que têm na força de trabalho, a propriedade através da qual ocorre a inserção no mercado de trabalho.

\section{A complexa organização do trabalho em classe social}


Esta parte do texto será baseada na análise do capítulo XIV do livro I de O Capital comparativamente ao capítulo $\mathrm{V}$, tomando como referência a análise realizada por Lessa (2006). Uma diferença fundamental do capítulo XIV para o capítulo V é que enquanto neste o trabalho é focado do ponto de vista "individual", naquele é considerado do ponto de vista "coletivo", ou seja, é considerada a divisão do trabalho. Então, se antes o processo de trabalho individual reunia várias funções, ao ser considerada a divisão do trabalho, aquelas funções foram separadas. Essa apartação inclui também "a separação entre trabalho manual e intelectual até tornarem-se inimigos" (MARX, 1985c, p. 105). Entretanto, o trabalho - intercâmbio orgânico entre homem e natureza - é reafirmado e se constitui em fundamento para a crítica do trabalho abstrato - a força de trabalho reduzida a mercadoria - ou do trabalho sob a ordem capitalista (LESSA, 2006, p. 01). $O$ processo de trabalho, por sua vez, continua igualmente como a atividade humana orientada a um fim, sendo que o produto do trabalho deixa de ser produto do trabalhador produtivo individual e passa a ser produto de um "trabalhador coletivo" (MARX, 1985c, p. 105).

Segundo Lessa (2006), trabalhador coletivo não seria a melhor tradução para gesamtarbeiter (termo utilizado por Marx no texto original). Já expressões tais como trabalhador conjunto, global ou combinado seriam mais adequadas, pois o termo trabalhador coletivo expressa uma relação de solidariedade entre os diversos segmentos dos trabalhadores. Na realidade, 0 trabalho realizado pelo trabalhador coletivo considerado por Marx não é aquele exercido solidariamente, pois, se assim fosse, não teria sentido considerar a existência de oposição entre trabalho manual e intelectual na condição de inimigos (LESSA, 2006, p. 06).

Concretamente, no interior do trabalhador coletivo há desde o trabalho propriamente intercâmbio com a natureza - bem como outras práxis sociais. Nesse contexto, Marx (1985c) entende que o trabalho coletivo se amplia e se estreita. Dado que se trata de uma realidade capitalista, passa a ser considerado produtivo o trabalho que produz mais-valia para o capitalista. Então, a ampliação do trabalho coletivo se dá pelo fato de que todas as práxis sociais que permitem participar da repartição da mais-valia passam a se consideradas produtivas e integrantes do trabalho coletivo. De outra parte, o estreitamento decorre do fato de que apenas o trabalho intercâmbio orgânico - produz e valoriza o capital (MARX, 1985c; LESSA, 2006).

Em contexto capitalista, costuma-se fazer uma identificação entre trabalhado coletivo e trabalho assalariado. Entretanto, o trabalho coletivo no sentido de trabalho assalariado não é homogêneo. Concretamente, são três as esferas do trabalho assalariado: um segmento é composto pelos que efetivamente operam o intercâmbio com a natureza; um outro segmento é composto pelos que embora não operem o intercâmbio com a natureza atuam em colaboração com os primeiros e, dessa forma, compõem também o trabalho coletivo e, por fim, tem-se um outro 
segmento formado por trabalhadores que "exercem a função exclusiva de controle" dos trabalhadores efetivamente produtivos sob a delegação de comando dos detentores do capital (LESSA, 2006, p. 14).

Os integrantes do proletariado são os "assalariados, partícipes do trabalho coletivo, que transformam a natureza" ou que produzem e valorizam o capital (LESSA, 2006, p. 14). Portanto, há uma clara distinção de função entre os que produzem a riqueza e os que exercem função de controle sobre aqueles. Efetivamente, os proletários exercem a função social de produtores do conteúdo material da riqueza que é repartida entre todas as classes sociais. Então, se a propriedade dos meios de produção é o critério demarcatório da burguesia em face aos que vendem a força de trabalho, a função social é o critério fundamental para estabelecer a diferenciação entre os que exercem o trabalho fundante - intercâmbio orgânico - e os que vivem do trabalho daqueles, seja como acontece com as diferentes frações da classe burguesa a partir da propriedade do capital, seja através de práxis sociais diversas exercidas sob a forma de trabalho assalariado para controle da força de trabalho ou em participação na divisão do trabalho para fazer circular a riqueza produzida ou ainda em atividades que visam a reprodução da ordem social vigente. Logo, entre a burguesia e o proletariado existe uma gama de segmentos que vai desde os assalariados que exercem controle sobre o proletariado, passa pelos assalariados envolvidos com as atividades de circulação, de prestação de serviços, de atividades vinculadas à estrutura do Estado e chega até as atividades desenvolvidas por camponeses e artesãos.

É recorrente a afirmação de que o proletariado é a classe efetivamente revolucionária, por se tratar da única que nada teria a perder com a superação do capitalismo. Esta assertiva encontra-se apoiada na ideia de que o proletariado é a classe que garante a reprodução de todas as classes sociais pelo fato de ser "a única classe que vive da riqueza produzida pelo seu trabalho" (LESSA, 2006, p. 23).

A discussão sobre as classes polares das sociedades capitalistas remete a uma temática relativamente polêmica no seio do marxismo: as classes médias. A princípio, é necessário destacar que nas obras 0 Manifesto, $O$ Dezoito brumário e Crítica ao programa de Gotta e Teorias da mais-valia Marx abordou esta temática.

\section{A classe média: entre a burguesia e o proletariado}

Segundo Hirano (2002), por classes médias Marx entendia vários agrupamentos sociais que se situam "entre a classe dominante (burguesia) e o proletariado" e que são denominadas de classes de transição e intermediárias (HIRANO, 2002, p. 150). As classes de transição dizem 
respeito, sobretudo, às classes com existência anterior ao capitalismo e que continuaram existindo após a afirmação do capitalismo. Seriam, então, as 'velhas classes médias' compostas pelos pequenos proprietários agrícolas, pequenos artesãos urbanos e por categorias de profissionais autônomos. As classes intermediárias, denominadas por Hirano (2002) de 'nova classe média', seriam produto típico da nova indústria e compostas pelo administrador, o gerente e o supervisor, tal como aparece em O Capital, Livro primeiro, capítulo 11 (MARX, 1985b; HIRANO, 2002, p. 172). $\mathrm{Na}$ verdade, ainda integram as classes intermediárias todos os demais segmentos do trabalho assalariado que não compõem o proletariado.

Um dos aspectos relativos às classes médias diz respeito ao seu caráter reacionário. $\mathrm{Na}$ obra Crítica ao programa de Gotha tal caráter é, a princípio, reafirmado quando repete passagem do Manifesto em que diz que "somente o proletariado é revolucionário". Entretanto, em seguida apresenta uma ressalva à afirmação anterior. Criticando o Programa de Gotha, Marx reafirmou 0 texto do Manifesto, escrevendo que "as 'classes médias ... tornam-se revolucionárias quando têm diante de si a perspectiva de sua passagem iminente para o proletariado'" (MARX e ENGELS, 19-a, p. 29; MARX, 19--c, p. 216; HIRANO, 2002, p. 171). Então, em outras circunstâncias as classes médias tenderiam a assumir posturas reacionárias. Entretanto, é importante destacar que as posições adotadas por determinadas classes em relação às outras depende sempre de situações políticas concretas.

Um outro aspecto relativo às classes médias diz respeito à tendência ao seu desaparecimento. Segundo Hirano (2002), consentaneamente às ideias de Marx, a tendência à polarização de classes entre burguesia e proletariado aconteceria não em decorrência do desaparecimento de todas as classes médias, mas das "velhas classes médias"' ou das classes de transição. O mesmo não diria respeito às "novas classes médias"” por serem "produtos típicos da grande indústria" e da nova 'ordem' (HIRANO, 2002, p. 172).

Na realidade, em outras obras de Marx (1980) são encontradas também referências às classes médias, que indicam a perspectiva do seu aumento. É este o caso da obra Teorias da mais-valia em duas de suas passagens. Na primeira, referindo-se a Ricardo afirma: $\mathrm{O}$ que

Ricardo Esquece de acentuar (é): o crescimento constante das classes de permeio (classes médias), situadas entre trabalhadores, de um lado, e capitalistas e proprietários das terras, do outro; vivem elas diretamente da renda (revenue) em escala cada vez maior e em grande parte; sobrecarregam a base trabalhadora e aumentam a segurança e o poder sociais das dez mil famílias de cima (MARX, 1980, p. 1007, texto nosso).

Na segunda, a alusão é feita à elaboração de Malthus. Afirma: 
Sua maior esperança - que ele mesmo designa de mais ou menos utópica - é que aumente a massa da classe média, e o proletariado (que trabalha) constitua um segmento relativamente cada vez menor da população total (embora cresça em termos absolutos). Este é na realidade o rumo que segue a sociedade burguesa (MARX, 1980a, p. 1118, grifo do autor).

Além disso, pode-se ainda afirmar que, à luz da elaboração de Marx, o próprio avanço das forças produtivas constitui-se em base material para a ampliação dos setores médios das sociedades, uma vez que proporcionalmente cada vez menos trabalhadores passam a se ocupar com a produção do conteúdo material da riqueza, de maneira que as funções de mando e controle sobre os trabalhadores e o excedente social crescente tendem a ser ampliadas. Então, a exposição precedente deixa evidente que não só as classes médias estão contempladas na teorização de Marx, como uma das interpretações, a partir do próprio autor, é a tendência ao crescimento deste segmento social.

O que se constata é que a obra de Marx fornece as linhas gerais para o estudo das grandes classes sociais em sociedades capitalistas ou para o estudo de classes de uma perspectiva macro. Certamente os estudos concretos podem revelar processos diferenciados de constituição das classes sociais, bem como especificidades na sua composição em cada momento específico da história. Entretanto, as peculiaridades das classes em distintos recortes geográficos - países, regiões, municípios - não cancelam os aspectos gerais constitutivos das classes sociais numa perspectiva macro tal como discutido ao longo da obra de Marx. De outra parte, é necessário reconhecer que as transformações ocorridas nas sociedades capitalistas desde Marx até a contemporaneidade, fizeram com que as grandes classes - capitalista, intermediária e proletária - experimentassem diferenciações internas e que, por isso, constituem importante objeto de investigação que possibilita enriquecer o estudo das classes sociais na atualidade.

Em que pese o teor da exposição acima, é necessário reconhecer que as previsões de Marx alusivas às 'antigas classes médias' não se concretizaram e que, além disso, as 'novas classes médias' embora contempladas não foram abordadas de modo exaustivo. Certamente, isto ocorreu pelo fato do mesmo somente haver abordado a questão das classes sociais no âmbito do tratamento de outras temáticas. Isto, entretanto, não anula a riqueza da macro-abordagem. Assim, é perfeitamente compreensível que as experiências concretas dos países quanto à ampliação das classes médias ao longo do século XX gerassem estudos focados nesses segmentos sociais.

Vários são os estudos que têm abordado as classes sociais em sociedades capitalistas no período recente, ou seja, da década de setenta até o momento atual. Dentre eles podem ser destacados: A estrutura de classes das sociedades avançadas (GIDDENS, 1975); As classes sociais no capitalismo de hoje (POULANTZAS, 1978); A nova classe média (MILLS, 1979); Classe, 
crise e o Estado (WRIGHT, 1981); The debate on classes (WRIGHT, 1989); Class counts (WRIGHT, 1997); Trabalho e capital monopolista (BRAVERMAN, 1977); Aspectos da crise social no Brasil dos anos oitenta e noventa (QUADROS, 2003); Espacialização de classes no Brasil (MAIA, 2006).

\section{Wrigth: uma fonte teórica para a análise da estrutura das classes sociais no Brasil}

Em que pese a importância das obras supracitados à compreensão das classes sociais na contemporaneidade, convém destacar neste momento, o estudo realizado recentemente por Santos (2002) sob o título "Estrutura de posições de classe no Brasil: mapeamento, mudanças e efeitos na renda". Neste estudo, Santos (2002) utiliza como principal autor de referência Erik Olin Wright e como base empírica as Pesquisas Nacionais por Amostra de domicílio (PNADs), realizadas nos anos de 1982 e 1986 pelo Instituto Brasileiro de Geografia e Estatística (IBGE) para elaborar um mapeamento da estrutura de classes sociais no Brasil. A ideia aqui defendida é que o autor conseguiu uma excelente aproximação da estrutura de classes no Brasil a partir da base empírica já referida. e, por esse motivo, o estudo em pauta, constitui-se em suporte fundamental para a pesquisa ora desenvolvida, embora esta tenha por base empírica os Censos Demográficos, em vez das Pesquisas Nacionais por Amostra de domicílio.

A princípio, é importante destacar que Santos efetuou vários ajustamentos às tipologias utilizadas por Wright, sobretudo em decorrência das especificidades das fontes de dados utilizadas. Entretanto, neste item do estudo não cabe tratar de tais modificações, mas do cerne do tratamento teórico utilizado pelo autor. Assim, procede-se, a seguir, a uma breve aproximação da elaboração teórica de Erik $\mathrm{O}$. Wright tendo como base o texto destinado ao referencial teórico apresentado por Santos (2002).

Embora tivesse preocupação com o estudo do conjunto das classes sociais, Wright precisou dar atenção especial a uma temática cara ao pensamento marxista: as classes médias. Dado que as classes médias constituem assunto controverso na literatura marxista é necessário destacar que Wright posicionou-se no debate como defensor da perspectiva segundo a qual as classes médias caracterizam-se, a princípio, por representarem "localizações contraditórias dentro das relações de classe"', sendo o caráter contraditório das localizações decorrente do compartilhamento de "características relacionais de duas classes distintas"'. O primeiro mapa de classes foi elaborado levando em consideração os processos de dominação e subordinação dentro 
da produção a partir da posse de capital monetário, de capital físico e de "trabalho" (SANTOS, 2002, p. 38).

Em seguida, Wright passou a considerar a exploração como o centro da sua análise de classe, sendo a ideia-chave a de que "a exploração material é determinada pelas desigualdades na distribuição dos ativos produtivos" (SANTOS, 2002, p. 38). Então, a posse de tais ativos tenderia a gerar interesses antagônicos, pois determinados segmentos sociais passam a desfrutar de boas condições de vida às expensas de outros. O entendimento é que os "Ativos produtivos são fatores ou recursos produtivos geradores de renda". Segundo esta acepção de ativos, a ideia de exploração seria, então, aplicável tanto aos proprietários de meios de produção, bem como a alguns segmentos das classes médias, relativamente aos produtores da riqueza social por serem detentores de ativos de qualificação. Seria, então, a desigualdade na distribuição desses ativos, a base para as "transferências de trabalho excedente" e para a estrutura de classes e os conflitos de classes (SANTOS, 2002, p. 43).

Embora chame a atenção para o fato de que "as diversas dimensões da desigualdade social não possam ser reduzidas à desigualdade de classes", Wright considera que "as relações de classe jogam um papel decisivo na moldagem das outras formas de desigualdade", como é o caso da desigualdade de renda, pois "as posições de classe moldam o modo como outras causas influenciam a renda" (SANTOS, 2002, p. 44). Portanto, ainda que as diferenças sociais tenham dimensões de cor/raça, de sexo e de idade, dentre outras, não estão completamente desconectadas das relações sociais.

Wright trabalhou também com a ideia de que no capitalismo, além da exploração capitalista havia espaço para a exploração não propriamente capitalista, embora the fosse subordinada. Então, ganha importância a ideia de "localizações contraditórias de classe". Essas localizações seriam exercidas pelos integrantes das posições intermediárias em função da "existência de ativos organizacionais". Considera a organização um ativo por implicar na "tomada de decisão coordenadora sobre uma complexa divisão técnica do trabalho" (SANTOS, 2002, p. 44). Neste contexto, o papel exercido pelos gerentes seria fundamental, em decorrência da participação nas relações de dominação e da "localização privilegiada de apropriação [...] dentro das relações de exploração", sendo que tal papel "garante-lhes a percepção de 'rendas de lealdade'" (SANTOS, 2002, p. 45).

Santos (2002) apresentou duas versões das tipologias de classe elaboradas por Wright, sendo uma denominada de "básica" e a outra de "desenvolvida". Alude, inicialmente, à diferença entre classes e localizações ou posições de classe. Afirma: as "classes caracterizam-se pela sua localização dentro das relações sociais de produção" enquanto que as localizações ou "ocupações 
representam posições definidas no âmbito das relações técnicas de produção" (SANTOS, 2002, p. 47), sendo que "as localizações de classe estão sempre estruturalmente interconectadas às relações de classe", por isso "a noção de estrutura de classes designa a organização de conjunto de relações e localizações de classe" (SANTOS, 2002, p. 50).

A tipologia de classe elaborada por Wright referente às sociedades capitalistas teve, no caso da versão básica, seis localizações de classe, enquanto na versão desenvolvida, teve doze localizações (SANTOS, 2002). Em ambos os casos, as tipologias foram elaboradas "em função da apropriação diferenciada de ativos em meios de produção, ativos de qualificação e relação com 0 exercício de dominação dentro da produção (caracterizados antes como ativos organizacionais)". Afirma que "a parte crítica [...] encontra-se [...] nas divisões internas entre os assalariados" (SANTOS, 2002, p. 49).

Pelo fato da tipologia desenvolvida constituir-se num aprofundamento da tipologia básica, a referência será àquela, por ser mais ampla. A primeira distinção quanto às posições de classes diz respeito ao controle dos meios de produção. Segundo este critério classificatório, tem-se, de um lado, os proprietários ou detentores de meios de produção e, de outro, os não-proprietários ou trabalhadores assalariados. No caso dos proprietários de meios de produção ou de ativos materiais, as posições de classe são: burguesia, pequenos empregadores e pequena burguesia.

O critério fundamental utilizado na classificação é o aporte de capital. No caso da primeira posição, a burguesia, tem-se aqueles cujo aporte de capital é suficientemente grande de modo que permite viver exclusivamente do trabalho de outrem. No caso da segunda, o aporte de capital atinge uma magnitude que permite empregar pessoas, mas impõe ainda a necessidade de "trabalhar". No caso da terceira, diz respeito a detentores de meios de produção, cujo aporte é insuficiente para empregar pessoas. Já a classe considerada intermediária ou classe com posição contraditória, tem as suas posições de classe definidas pelo critério de relação com a autoridade. São seis as posições nas quais são classificados gerentes e supervisores. Essas posições são adjetivadas de especialistas, qualificados e não qualificados e, portanto, como resultado tem-se três tipologias para gerentes e três para supervisores. As posições de gerentes e supervisores caracterizam-se pelo exercício de algum nível de autoridade em face aos trabalhadores. Entretanto, o caráter distintivo de tais posições é que se os supervisores assumem posição de autoridade sobre os trabalhadores, os gerentes caracterizam-se por exercer também autoridade sobre segmentos subordinados e por participarem da tomada de decisões estratégicas nas organizações. Por fim, na tipologia de classes em pauta, tem-se os segmentos compostos pelos não-gerentes especialistas, os trabalhadores qualificados e, na base da estrutura, os trabalhadores não qualificados. 
Santos (2002) além de apresentar uma resenha das "críticas ao esquema de classes de Erik Olin Wright", procedeu ainda a uma reelaboração das tipologias daquele autor, considerando as especificidades das fontes de que fez uso e, ademais, levando em consideração as especificidades da realidade que se constituiu em objeto do seu estudo. Finalizando, é importante destacar que Santos (2002) defende a relevância do trabalho de Wright, sobretudo por se tratar de estudo voltado à "pesquisa empírica sistemática" e por se tratar de teoria e tipologia que "inscrevem-se em uma obra aberta e em progresso" (SANTOS, 2002, p. 68). Foi com base nessa avaliação que Santos (2002) utilizou Erik Olin Wright como autor de referência para o estudo de posições de classe no Brasil.

\section{Considerações Finais}

Como registrado no corpo do presente artigo ainda persiste entre os estudiosos das classes sociais o debate sobre a existência ou não em Marx de um estudo mais aprofundado sobre classes sociais. Para os que sustentam a tese da inexistência de uma análise robusta sobre classes sociais em Marx, o fazem argumentando que o esboço de sua análise - As classes - que se encontra na obra O Capital, Livro III, capítulo LII, não foi devidamente concluído. Ademais, para alguns desses críticos de Marx, a exemplo de GIDDENS (1975) e (POULANTZAS, 1978) as transformações políticas, sociais e econômicas do modo de produção capitalista entre o final do século XIX e o decorrer do século XX não podem ser explicadas pelas poucas reflexões de MarX adstritas ao histórico século XIX.

Entre os estudiosos que argumentam que existe em Marx uma teoria das classes sociais com suficiente capacidade explicativa encontra-se Hirano (20020) e Lessa (2006). Ambos os autores admitem que para além de $O$ Capital na ampla obra de Marx encontra-se a discussão sobre diferentes agrupamentos sociais para que se entenda sua manifestação nos países capitalistas, inclusive na contemporaneidade.

Em Marx, as classes sociais são produto notadamente políticos e sociais de formações econômicas concretas. Marx deixou claro que a forma social (histórica) dos proprietários feudais (senhores feudais e eclesiásticos) se "contrapunham" aos servos, vassalos. Essa forma concreta de manifestação de classe ou de estamentos de classes foi superada, negada pela ascensão do modo de produção capitalista. Neste novo modo de produção os antagonismos e contradições de toda natureza entre os agrupamentos sociais estariam mais acirrados entre os capitalistas burgueses donos dos meios e instrumentos de produção e os trabalhadores proprietários da mercadoria força de trabalho. 
Enfatiza-se que não escapou da análise de Marx a presença de agentes que não se enquadravam conceitualmente nem na classe dos proprietários burgueses (urbanos e rurais) nem na classe trabalhadora: os agentes médios ou como tornou-se comum chamar, a classe média. Acrescente-se a esta análise das classes sociais de Marx a presença de algumas subdivisões no interior dessas classes sociais como, por exemplo, a pequena burguesia, 0 administrador e 0 supervisor.

Assim, é possível concluir que a discussão sobre a existência ou não em Marx de uma teoria sobre classes sociais parece continuar viva e atual. O que deve ser observado com apurada atenção é que as análises sobre as classes sociais em Marx aparecem de forma pulverizada dentro de sua obra podendo ser encontradas férteis reflexões sobre o fenômeno em 0 Dezoito Brumário, no pouco conhecido A revolução Espanhola, em O Manifesto do Partido Comunista, na Crítica ao Programa de Gotta, nas Teorias da Mais-Valia etc. Assim, se em O Capital Marx ficou devendo uma reflexão consistente e acabada sobre as classes sociais, o mesmo não se pode dizer do conjunto de sua obra que ainda hoje fertiliza e ilumina os caminhos de novas investigações sobre as classes sociais tendo, talvez, como único empecilho a superação da sociedade de classes.

\section{REFERÊNCIAS BIBLIOGRÁFICAS}

BOTTOMORE, Tom. Aristocracia operária, Burguesia, Casta, Classe, Classe dominante, Classe dominante, Classe média, Classe operária, Lupemproletariado, Luta de classes. In:

BOTTOMORE, Tom (Editor). Dicionário do pensamento marxista. Rio de Janeiro: Jorge Zahar Editor, 1997.

BRAVERMAN, Harry. Trabalho e capital monopolista. Rio de Janeiro: Zahar, 1977. GIDDENS, Anthony. A estrutura de classes das sociedades avançadas. Rio de Janeiro: Zahar, 1975.

HIRANO, Sedi. Castas, estamentos e classes sociais: introdução ao pensamento sociológico de Marx e Weber. $3^{a}$. Ed., São Paulo: Unicamp, 2002.

LESSA, Sergio. Trabalhadores e proletários no capitalismo contemporâneo. 2006. (Digi) MAIA, Alexandre Gori. Espacialização de classes no Brasil: uma nova dimensão para a análise social. Campinas, Instituto de Economia, 2006. (Tese de Doutoramento).

MANDEL, Ernest. $O$ capitalismo tardio. 2. ed., São Paulo: Nova Cultural, 1985. (Os Economistas).

MARX, Karl e ENGELS, Friedrich. O manifesto do partido comunista. In: Karl Marx e Friedrich Engels. Obras escolhidas. São Paulo: Alfa-Ômega, [19--a]. MARX, Karl. Crítica ao programa de Gotha. In: Karl Marx e Friedrich Engels. Obras escolhidas. São Paulo: Alfa-Ômega, [19--c].

MARX, Karl. 0 capital: crítica da economia política. 2. Ed., São Paulo: Nova Cultural, 1985-6. (Coleção os Economistas, L3, t2). 
MARX, Karl. 0 capital: crítica da economia política. 2. Ed., São Paulo: Nova Cultural, 1985b. (Coleção os Economistas, L1, t1).

MARX, Karl. 0 capital: crítica da economia política. 2. Ed., São Paulo: Nova Cultural, 1985c. (Coleção os Economistas; L1, t2).

MARX, Karl. 0 dezoito brumário de Luís Bonaparte. In: Karl Marx e Friedrich Engels. Obras escolhidas. São Paulo: Alfa-Ômega, [19--b].

MARX, Karl. Teorias da mais-valia: história crítica do pensamento econômico. Rio de Janeiro: Civilização Brasileira, 1980. (L4, v2).

MARX, Karl. Teorias da mais-valia: história crítica do pensamento econômico. Rio de Janeiro: Civilização Brasileira, 1980a. (L4, v3).

MILLS, Wright. A nova classe média. 3. ed., Rio de Janeiro: Zahar, 1979.

POULANTZAS, Nicos. As classes sociais no capitalismo de hoje. Rio de Janeiro: Zahar, 1978.

QUADROS, Waldir. Aspectos da crise social no Brasil dos anos oitenta e noventa.

Campinas, 2003. Tese (Livre Docência) - Instituto de Economia, Universidade Estadual de Campinas.

SANTOS, José Alcides Figueiredo. Estrutura de posições de classe no Brasil: mapeamento, mudanças e efeitos na renda. Belo Horizonte: Editora da UFMG; Rio de Janeiro: IUPERJ, 2002. SCOTT, John. Corporations, classes and capitalism. [s.I.]: [s.n.], 1979.

WRIGHT, Erik Olin e t. al. Class counts: comparative studies in classes analysis. Cambridge: Cambridge University Press, 1997.

WRIGHT, Erik Olin e t. al. The debate on classes. London: Verso, 1989.

WRIGHT, Erik Olin. Classe, crise e o Estado. Rio de Janeiro: Zahar, 1981.

\section{Recebido para avaliação em 07 de janeiro de 2020.}

Aceito para publicação em 05 de março de 2021.

\section{AS CLASSES SOCIAIS EM MARX: retrospectiva e atualidade Resumo}

$O$ artigo tem como principal objetivo registrar a discussão e o entendimento sobre classes sociais em Marx e a possível atualidade da sua abordagem. A hipótese é que a discussão sobre classes sociais empreendida principalmente em O Capital, O Manifesto Comunista e O Dezoito Brumário constituem os elementos essenciais sobre a teorização a respeito das classes sociais em sociedades capitalistas. A título de considerações finais pode-se afirmar que aquele corpo teórico foi continuamente atualizado por seguidores de Marx para dar conta da fragmentação e estratificação ocorridas ao longo do século XX e princípio do terceiro milênio, demonstrando a potência da formulação originária.

Palavras-chave: Classes sociais; Sociedade; Formação Econômica; Capitalismo.

SOCIAL CLASSES IN MARX: retrospective and contemporaneity

Abstract

The main objective of the article is to record the discussion and understanding of social classes in Marx and the possible contemporaneity of his approach. The hypothesis is that the discussion about social classes undertaken mainly in The Capital, The Communist Manifesto and The 
Eighteenth Brumaire constitutes the essential elements about Marx's theorization regarding social classes in capitalist societies. As final considerations, it can be said that this theoretical body was continuously updated by his followers to account for the fragmentation and stratification that occurred throughout the $20^{\text {th }}$ century and the beginning of the third millennium, demonstrating the power of the original formulation.

Key words: Social classes; Society; Economic Formation; Capitalism. 